\title{
Nongenic, bidirectional transcription precedes and may promote developmental DNA deletion in Tetrahymena thermophila
}

\author{
Douglas L. Chalker ${ }^{1,2}$ and Meng-Chao Yao \\ Division of Basic Sciences, Fred Hutchinson Cancer Research Center, Seattle, Washington 98109, USA
}

\begin{abstract}
A large number of DNA segments are excised from the chromosomes of the somatic nucleus during development of Tetrahymena thermophila. How these germline-limited sequences are recognized and excised is still poorly understood. We have found that many of these noncoding DNAs are transcribed during nuclear development. Transcription of the germline-limited $M$ element occurs from both DNA strands and results in heterogeneous transcripts of $<200 \mathrm{~b}$ to $>1 \mathrm{~kb}$. Transcripts are most abundant when developing micro- and macronuclei begin their differentiation. Transcription is normally restricted to unrearranged DNA of micronuclei and/or developing nuclei, but germline-limited DNAs can induce their own transcription when placed into somatic macronuclei. Brief actinomycin D treatment of conjugating cells blocked M-element excision, providing evidence that transcription is important for efficient DNA rearrangement. We propose that transcription targets these germline-limited sequences for elimination by altering chromatin to ensure their accessibility to the excision machinery.
\end{abstract}

[Keywords: DNA rearrangement; intergenic transcription; ciliates; nuclear development]

Received February 1, 2001; revised version accepted March 26, 2001.

A remarkable process of DNA rearrangement occurs during development of Tetrahymena thermophila in which 6000 DNA segments are coordinately excised from the newly forming somatic nucleus (reviewed in Coyne et al. 1996; Yao et al. 2001). Like other ciliated protozoa, Tetrahymena contain two types of nuclei, a somatic macronucleus and a germline micronucleus. During vegetative growth, all gene expression occurs from the macronucleus, whereas the micronucleus remains transcriptionally silent (Gorovsky and Woodard 1969). In each sexual generation the macronucleus is destroyed, and a new micronucleus and macronucleus are created, each deriving its genome from micronuclear DNA. In new micronuclei the five pairs of chromosomes remain unaltered, whereas in the macronuclear precursors the chromosomes are fragmented and $\sim 15 \%$ of the germline DNA is eliminated by site-specific DNA deletion. After these DNA rearrangements, the macronuclear chromosome fragments are amplified to $\sim 50$ copies/nucleus.

The DNA segments eliminated from the developing macronucleus, known as deletion elements, consist of

Present address: ${ }^{1}$ Box 1137, Dept. of Biology, One Brookings Drive, Washington University, St. Louis, MO 63130, USA.

${ }^{2}$ Corresponding author.

E-MAIL dchalker@biology.wustl.edu; FAX (314) 935-4432.

Article and publication are at www.genesdev.org/cgi/doi/10.1101/ gad.884601. either unique or moderately repetitive sequences (Yao and Gorovsky 1974). These predominantly noncoding DNAs vary greatly in size, ranging from about $600 \mathrm{bp}$ to greater than $13 \mathrm{kbp}$. Nine of the estimated 6000 deletion elements have been sequenced and found to have little or no sequence homology (for review see Yao et al. 2001). Extensive analyses of two of these, the $\mathrm{M}$ and $\mathrm{R}$ elements, have revealed that the boundaries of DNA deletion are delimited by pairs of cis-acting sequences located a short distance outside of the ends of each element (Chalker et al. 1999; Godiska et al. 1993; Godiska and Yao 1990). Notably, the exact sequence of these functionally similar boundary determinants is different for each element; a fact that further highlights the extraordinary diversity of these germline-limited sequences.

Three proteins, named Programmed DNA degradation proteins (Pddps) have been identified that likely play a role in DNA deletion (Madireddi et al. 1996; Madireddi et al. 1994; Nikiforov et al. 2000; Smothers et al. 1997). Two of these, Pdd1 and Pdd3, are chromodomain-containing proteins, which has led to the suggestion that DNA deletion involves specialized chromatin structure (Madireddi et al. 1996; Nikiforov et al. 2000). Targeted gene disruption of Pdd1 and Pdd2 showed that expression of these genes during the first $8 \mathrm{~h}$ of conjugation is required for successful DNA elimination (Coyne et al. 1999; Nikiforov et al. 1999). 
Whereas some of the regulatory sequences and proteins involved in DNA deletion have been described, we have yet to gain clear insight into how the cell recognizes each of the $\sim 6000$ diverse DNA elements as different from the $\sim 85 \%$ of the genome that is retained in the macronucleus. As described below, we have uncovered unexpected transcription of these predominantly noncoding sequences. We characterize the transcription of the $\mathrm{M}$ element and other germline-limited sequences of Tetrahymena. This transcription is developmentally regulated and occurs before the elimination of these sequences during conjugation. We discuss how this unconventional transcription may participate in the extensive DNA rearrangements of the Tetrahymena genome.

\section{Results \\ Conjugation-specific, nongenic transcription of the Melement}

Although the micronuclear genome is transcriptionally silent during Tetrahymena vegetative growth, the transcription of micronucleus-limited sequences during nuclear development has been largely unexplored. We can induce synchronous development by simply mixing prestarved cells of complementary mating types (Bruns and Brussard 1974). This initiates conjugation that triggers an intricate series of nuclear events, culminating with loss of the parental macronucleus within each cell and creation of a new macronucleus and micronucleus entirely from germline DNA of micronuclei (Martindale et al. 1982; Ray 1956) (see Fig. 1B). Within each conjugating pair, micronuclei undergo meiosis, and one haploid nucleus in each partner is selected as the gametic nucleus. After mitotic division, one haploid nucleus from each cell is transferred to its partner, then karyogamy of stationary and exchanged nuclei creates zygotic diploid nuclei of identical genotypes in each cell. These nuclei divide twice mitotically, and the mitotic products differentiate into either micronuclei or macronuclei. The prezygotic nuclear events are completed within the first 5 to $6 \mathrm{~h}$ of conjugation (Martindale et al. 1982), and DNA rearrangements occur in developing macronuclei between 12 and $14 \mathrm{~h}$ (Austerberry et al. 1984). We investigated transcription of the extensively characterized $M$ element, which is excised in one of two alternative forms of either $0.6 \mathrm{kbp}$ or $0.9 \mathrm{kbp}$ that share a common right boundary, but have different left boundaries (Austerberry et al. 1984; Austerberry and Yao 1988) (see diagram in Fig. 1). We isolated total RNA from Tetrahymena cells either during vegetative growth, starvation, or at different times after the initiation of conjugation and performed Northern blot analysis using strandspecific probes complementary to the plus or minus strand of the germline-limited $\mathrm{M}$ element (Fig. 1A). No transcription of the element was detected in vegetative cells or starved cells before conjugation as expected because the $\mathrm{M}$ element is located exclusively in the transcriptionally silent micronucleus. In contrast, within the first few hours of conjugation, we detected M element- specific transcripts. Transcripts were apparent starting in prophase of meiosis I ( 2 to $3 \mathrm{~h}$ of conjugation), and continued to increase in abundance during the early stages of conjugation at least until zygotic nuclei had formed and given rise to the precursors of the new micronucleus and macronucleus (between 5 and $7 \mathrm{~h}$; see Fig. 1B).

These M-element transcripts are unusual in several respects. Their size distribution is quite broad, ranging from $<200 \mathrm{~b}$ to $>1 \mathrm{~kb}$. A marked decrease in this distribution is apparent between 5 and $7 \mathrm{~h}$ of conjugation. Furthermore, transcription occurs bidirectionally as hybridization with probes specific for either strand reveals a similar, although not identical, accumulation of transcripts (Fig. 1A). One obvious difference is that plus strand transcripts were most abundant at $5 \mathrm{~h}$, whereas minus strand transcripts were most abundant at $7 \mathrm{~h}$. The plus strand probe also detects an $\sim 3 \mathrm{~kb}$ transcript in the 11 and $13 \mathrm{~h}$ time points that we believe may be the product of read-through transcription from a neighboring gene. Given the unconventional hybridization pattern, it was crucial to rule out any possibility that we might be detecting DNA rather than RNA. RNAse treatment eliminated all hybridizing material, whereas DNAse treatment did not alter the observed hybridization pattern of the M-element probes (Fig. 1C). Therefore, the hybridization observed is indeed the result of M-element transcription.

It is important to note that the $\mathrm{M}$ element is $76.5 \%$ $\mathrm{A}+\mathrm{T}$ and shows little potential to express a translatable RNA (Austerberry and Yao 1988). Like most other micronucleus-limited sequences that have been described, it appears to be a noncoding sequence. Therefore, Melement transcription is unlikely to be associated with gene expression. The heterogeneous size distribution is not simply because of degradation of the RNA during sample preparation, because several gene-specific probes hybridize to discrete transcripts of the expected sizes (Fig. 1A). Furthermore, Northern blot analysis of RNA isolated from several independent matings showed the same transcript heterogeneity (data not shown).

To further analyze these M-element transcripts, we have made several attempts using primer extension and RNAse protection analyses to map the start sites of transcription. We failed to detect a major initiation site for transcripts from either strand (data not shown). If all transcripts of one polarity had identical $5^{\prime}$ ends, we would have detected such RNAs, because these analyses are generally more sensitive than Northern blot analysis. It is likely that the M-element transcripts have variable 5 ' ends, resulting from either multiple transcription initiation sites or from unusually rapid degradation.

From the above hybridization results, it is not obvious which part of the element might be included in the transcription unit. The largest transcripts detected are $>1 \mathrm{~kb}$ and are therefore larger than the entire germline-limited sequence. Furthermore, both strands are transcribed so that there are at least two distinct sets of transcripts. One possibility is that all transcription begins within the $\mathrm{M}$ element and extends in both directions for various 
distances into flanking DNA. However, the results of the following reverse transcription/polymerase chain reac-
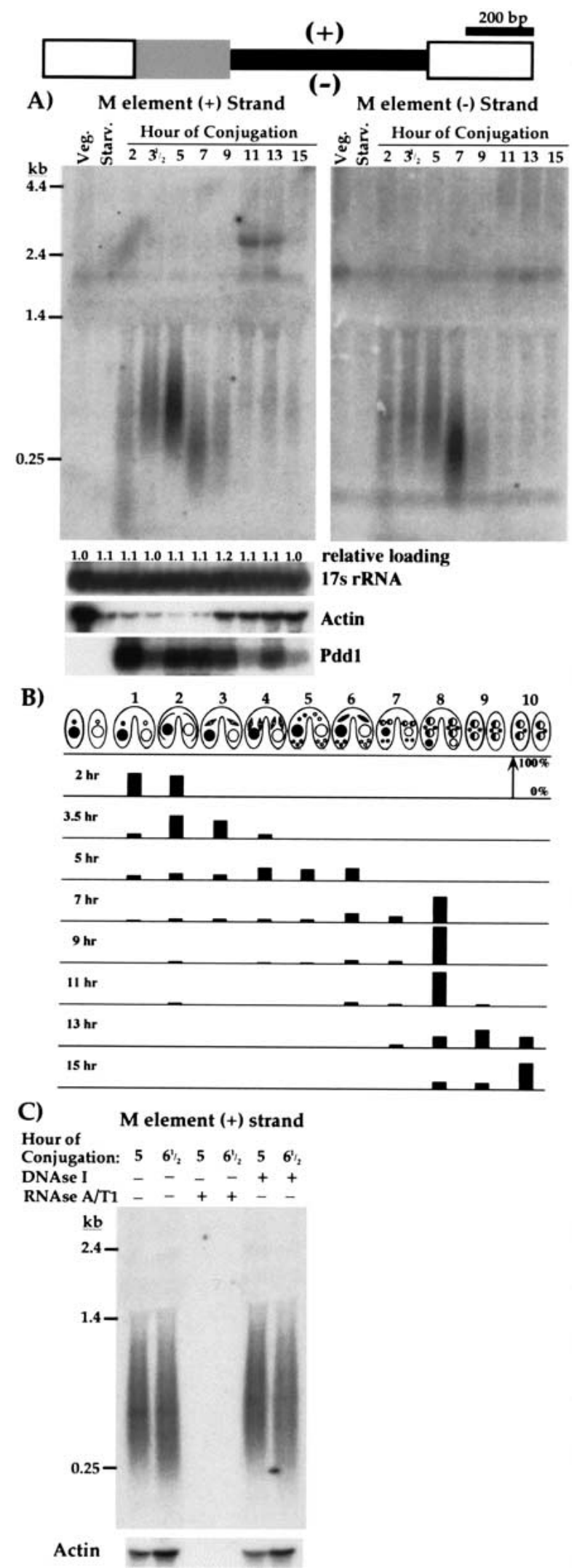

tion (RT-PCR) analysis are more consistent with transcription starting in the flanking DNA and continuing into the element. We reverse transcribed RNA, isolated when transcripts are most abundant $(6 \mathrm{~h})$, using $\mathrm{M}$ element-specific oligonucleotide primers, and used these complementary DNAs (cDNAs) as templates for two rounds of PCR using nested primers. When we used PCR primers flanking the element, we detected minus-strand transcripts that spanned the entire $0.6 \mathrm{kbp}$ germline-limited DNA (Fig. 2A). The largest transcripts detected were at least $1.1 \mathrm{~kb}$, which is consistent with the size of the larger transcripts observed on Northern blots (Fig. 1A). Similarly, we detected plus-strand transcripts that initiated outside of the germline-limited sequence that spanned most of the element (Fig. 2B). While we cannot say that transcription initiation is restricted to the flanking region, it appears that many of the $5^{\prime}$ ends of these transcripts lie outside of the germline-limited DNA. The specificity of this PCR was assessed by sequence analysis of eight independent cloned products, which verified that we had amplified M-element transcripts /data not shown).

To determine the distribution and sequence of the $3^{\prime}$ termini of these M-element RNAs, we cloned the ends of

Figure 1. The $M$ element is bidirectionally transcribed during conjugation. In the diagram of the $\mathrm{M}$ element at the top, the narrow black box represents the $0.6 \mathrm{kbp}$ micronucleus-limited region; the wide, shaded box indicates the $0.3 \mathrm{kbp}$ alternatively eliminated region; the wide, open boxes depict the macronucleus-destined sequences flanking the element. We have arbitrarily designated plus (top) and minus (bottom) strands for the element. (A) Northern blots of total RNA (15 $\mu \mathrm{g} / \mathrm{lane})$ isolated from vegetative, starved, and synchronously conjugating Tetrahymena cells, as indicated above each lane, were hybridized with riboprobes specific to either the plus (left panel) or minus strand (right panel) of the germline-limited sequence. The two panels are separate blots each containing equal aliquots of identically treated RNA. To control for loading uniformity and RNA integrity, blots were stripped and rehybridized with probes specific for 17S rRNA, Actin RNA, and Pdd1 RNA, and the results for the left panel are shown. Quantitation of the 17s rRNA hybridization relative to that of vegetative cell RNA is given above each lane to indicate the relative loading. (B) The percentage of pairs in each cytological stage was determined by fixing an aliquot of cells at the time of RNA isolation in $70 \%$ ethanol followed by staining with DAPI (4',6-diamino-2-phenylindole dihydrochloride). Within the first hour after mixing, $>85 \%$ of cells paired. At least 100 pairs at each time point were examined by fluorescence microscopy. The developmental stages of conjugating cells were described initially by Martindale et al. (1982) and are as follows: (1) cell pairing, (2) crescent stage (prophase meiosis I), (3) meiosis I, (4) meiosis II, (5) prezygotic mitosis/nuclear exchange, (6) postzygotic mitosis, (7) macronuclear development I (Mac I), (8) Mac II, (9) Mac II-pair separation, and (10) Mac III. (C) Total RNA isolated from 5 or $6.5 \mathrm{~h}$ conjugating cells was treated with RNAseA and T1 or DNAseI before Northern blot analysis as indicated. This blot was hybridized with the plus-strand-specific M-element probe. Identical results were observed with the minus-strand probe (data not shown). Control hybridization with an actin probe is shown below each lane. For blots in $A$ and $C$, the positions of migration of RNA size standards (GIBCO-BRL) are indicated to the left. 


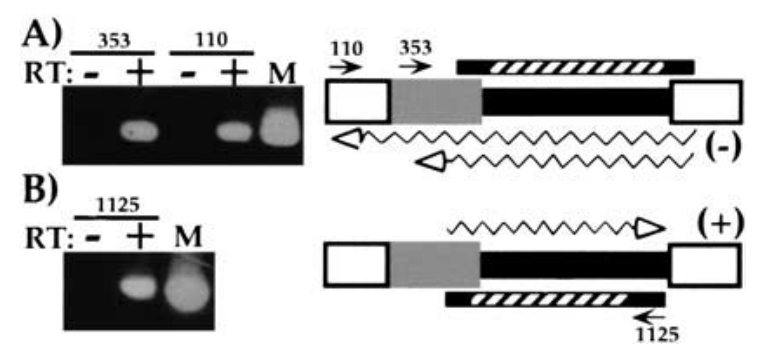

Figure 2. Transcripts initiated outside the $0.6 \mathrm{kbp}$ germlinelimited DNA. Representative RT-PCR reactions used to determine the extent of the transcribed region are shown to the left. The locations of the RT primers (arrows) and the regions of the $M$ element amplified (bars) are shown on the diagrams to the right. The M-element shading is as described in Figure 1. The hatched bars denote the regions amplified in the second-round PCR; the solid bar extensions indicate the additional region amplified in the first round of PCR. (A) Minus-strand transcripts were reverse transcribed using M-element-specific oligonucleotides M110-129 or M353-371. (B) Plus-strand transcripts were reverse transcribed with oligonucleotide M1125-1104. All PCR reactions were performed either with or without prior reverse transcription of RNA as indicated. Lane $M$ of each shows PCR reactions using M-element DNA as a positive control for amplification. The inferred minimal size of transcripts amplified is indicated by the wavy arrows drawn either below $A$ or above $B$ in each diagram.

several transcripts using RNA ligation-mediated RTPCR (see Materials and Methods). The positions of the six plus-strand ends and two minus-strand ends that we isolated are illustrated in Figure 3. No two independently amplified ends from either strand terminated at the same location. All six plus-strand ends terminated within the $0.6 \mathrm{kbp}$ germline-limited region, with five of the six clustered in the middle $200 \mathrm{bp}$. The M-element primers used to amplify these ends corresponded primarily to sequences outside the germline-limited DNA, which again indicated that transcription initiated in flanking DNA. For the two minus-strand ends recovered, one terminated within the germline-limited DNA and one nearly $200 \mathrm{bp}$ outside the left-most deletion boundary. None of the eight ends showed evidence of polyadenylation. In contrast, the 3' ends of mRNAs from three different genes ( $\mathrm{SerH} 3$ and two genes of unknown function), recovered in control amplifications, all showed polyadenylation (data not shown). We conclude the Melement transcripts are not polyadenylated and that there is no major stable end.

\section{Germline-limited sequences stimulate nongenic transcription}

Our analyses above indicated that a substantial fraction of transcripts start in DNA flanking the $\mathrm{M}$ element. This places transcription initiation in sequences that are found in both micro- and macronulcei. If transcription is indeed important for DNA deletion, we would predict that transcription should be restricted to the unrearranged, germline DNA of developing nuclei. To determine whether transcription of the M-element region occurs exclusively from micronuclear DNA, we monitored transcription in both wild-type cells and nullisomic cells (Nulli 4) that have normal macronuclei, but have micronuclei missing chromosome 4 on which the $\mathrm{M}$ element is located (Cassidy-Hanley et al. 1994). For this purpose, we developed a semiquantitative RT-PCR assay to compare directly transcript levels in equivalent RNA samples isolated from different strains. As a template for RT-PCR, we used pooled RNA isolated from 3.5, 5, and $7 \mathrm{~h}$ conjugating cells. In wild-type cells as predicted from the previous analyses, we detected transcription from both the $\mathrm{M}$ element and its immediate flanking DNA. In contrast, we could not detect any corresponding transcription in conjugating Nulli 4 cells. Even though the transcriptionally active macronuclei of the Nulli 4 cells contain the sequence corresponding to the $\mathrm{M}$ element flanking DNA detected by RT-PCR samples M1 and M4

Figure 3. M-element transcripts have heterogeneous, nonpolyadenylated $3^{\prime}$ termini. The $3^{\prime}$ termini of several M-element transcripts were mapped by RNA ligation-mediated PCR. The PCR products generated were cloned and sequenced. Representative reactions are shown in $A$. Identical reactions were performed either with or without initial reverse transcription or with pretreatment with RNAseA and T1 as indicated. After two rounds of PCR, specific products were detected by Southern blot analysis using an M-element probe. The position of the six plus-strand and two minus-strand 3 ' termini are numbered on the diagram of the $M$ element shown in $B$. The description of the M-element dia-

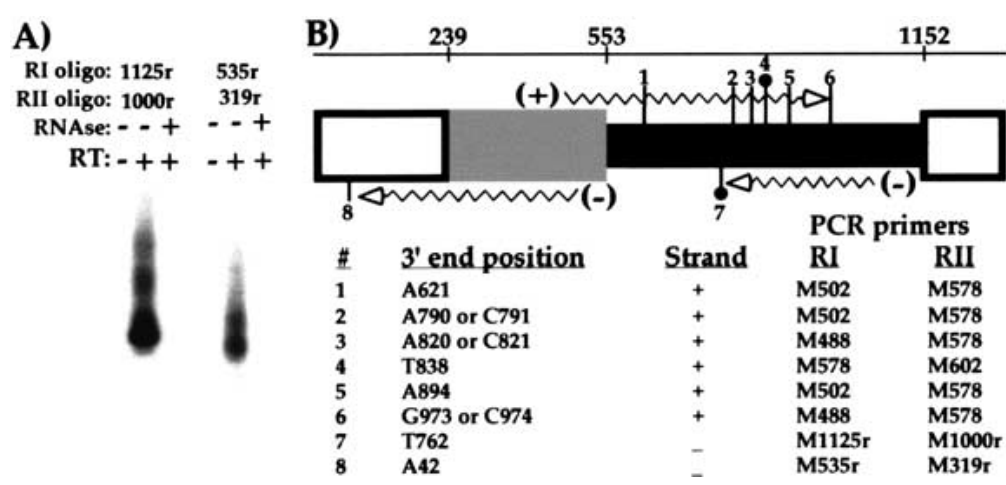
gram is given in Figure 1. For reference, the nucleotide positions of the boundaries of the M element as defined by the published sequence (Austerberry and Yao 1988) are given on the number line at the top. The two ends, \#4 and \#7, recovered using the BamHI sequence tagged ligation oligonucleotide (see Materials and Methods) are denoted by the solid circle. The exact nucleotide position of each end as well as the polarity of the transcript is listed below the diagram. In three cases, the exact end of the transcript was ambiguous because the terminal cytosine could have come from the transcript or the ligated oligonucleotide. The two M-element primers used in nested PCR to amplify each end are also given. In no case were extra A nucleotides observed that would indicate polyadenylation of these transcripts. 
(Fig. 4), we only found evidence of transcription of these regions in wild-type cells. Thus we conclude that all detectable transcription, including that of flanking DNA present also in macronuclei, occurs on the unrearranged DNA of micronuclei and/or developing nuclei. The lack of transcription in Nulli 4 cells is unlikely because of a nonspecific defect in developmental progression because of the missing micronuclear chromosome 4. Cells nullisomic for micronuclear chromosomes complete the prezygotic and early postzygotic events of conjugation with the same kinetics as wild-type cells (Ward et al. 1995), and the majority of Nulli 4 pairs in this mating progressed to at least stage I of macronuclear development (see description of conjugation in Fig. 1B). Therefore, the nuclear events occurring during the time in which we detect $\mathrm{M}$-element transcription are similar in both Nulli 4 and wild-type cells.

The above results raised the possibility that cis-acting sequences, which are necessary to induce this nongenic transcription, are located within the germline-limited DNA. If this is so, then an M-element copy placed into the macronucleus might be transcribed during conjugation. In previous work, we introduced vectors containing micronucleus-limited sequences into macronuclei and showed that their presence blocked elimination of the homologous germline-limited sequences from developing nuclei during the subsequent conjugation (Chalker and Yao 1996). Using this form of epigenetic regulation to block M-element excision, we generated strains that contain the normally micronucleus-limited $0.6 \mathrm{kbp}$ sequence of the $\mathrm{M}$ element in the macronucleus, and then asked whether this macronuclear $\mathrm{M}$ element is transcribed. In these "M+" strains, the $M$ element-containing regions of the micronucleus and the macronucleus are identical in sequence; however, because of the polyploidy of the macronucleus, in total these strains contain
15 to 20 times more copies than found in wild-type strains. Therefore, if the $\mathrm{M}$ element in the macronucleus is transcribed, we should detect a dramatic increase of M-element transcripts in these $M+$ strains. We compared transcript abundance present in equivalent amounts of RNA isolated from mating $\mathrm{M}+$ cells and wild-type cells using our semiquantitive RT-PCR assay (Fig. 4). We ob served a $>60$-fold increase in transcript levels of the germline-limited region in conjugating $\mathrm{M}+$ cells, indicating that this sequence can induce its own transcription when it is present in the macronucleus. This stimulation of transcription does not appear to extend significantly into the immediate flanking DNA as we did not observe this large increase in transcripts spanning the sequences monitored with PCR reactions M1, M2, and M4 (Fig. 4). Therefore, the transcripts that accumulate from the $M$ element in the macronucleus are qualitatively different from the transcripts from the germline genome. Nevertheless, the data clearly indicate that the germline-limited $\mathrm{M}$ element carries the sequences in cis to induce its own transcription. This ability to stimulate nongenic transcription appears to be a property shared with the adjacent germline-limited $\mathrm{R}$ element (described below).

\section{Nongenic transcription appears to be a general property of germline-limited DNA}

The estimated 6000 germline-limited sequences of the Tetrahymena micronucleus consist of either unique or moderately repetitive sequences (Yao and Gorovsky 1974). If this unconventional transcription plays a role in DNA deletion, it is likely that elements other than the $\mathrm{M}$ element are similarly transcribed during conjugation. A second well-characterized eliminated sequence, the $1.1 \mathrm{kbp}$ R element, is located $\sim 2.7 \mathrm{kbp}$ to the right of the $\mathrm{M}$ element in the germline genome. When we probed

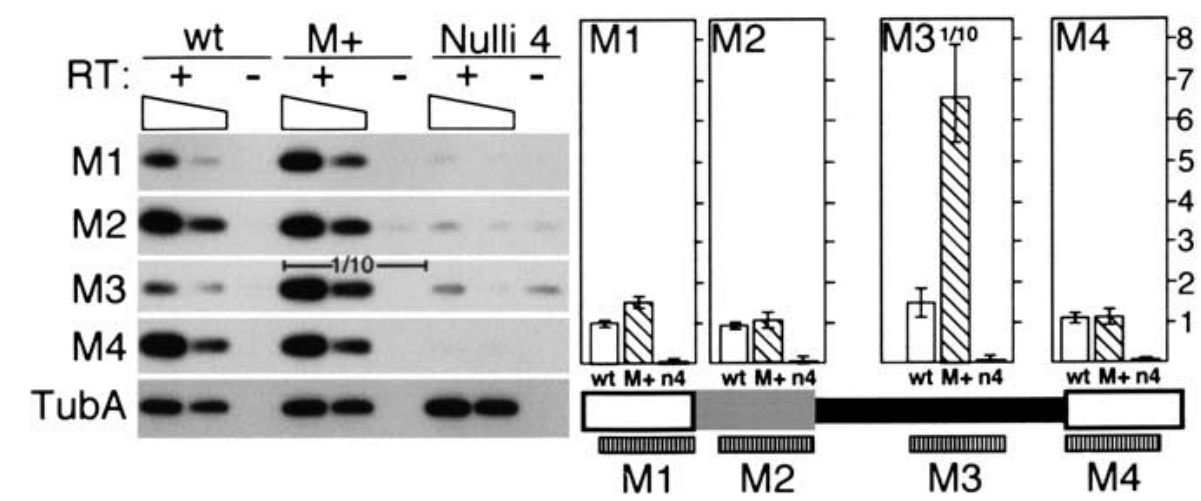

Figure 4. The $\mathrm{M}$ element can induce transcription. The transcription of the $\mathrm{M}$ element and immediate flanking DNA was compared between wild-type, $\mathrm{M}+$ (macronuclei containing copies of the M element), and Nulli 4 (micronuclei lacking chromosome 4) strains using semiquantitative RT-PCR. Transcription through four 200 bp regions of the element designated M1 through M4 was assayed. For + RT reactions, both the equivalent of $1 \mu \mathrm{g}$ total RNA (left lane of each) and $0.3 \mu \mathrm{g}$ of RNA (right lane of each) was assayed, which is indicated by the sloping box. After amplification, PCR products were detected by Southern blot analysis using an M-element probe. Equal reaction amounts were loaded in each lane except for the $\mathrm{M} 3$ reaction of $\mathrm{M}+$ strains for which one-tenth the amount was loaded to allow for accurate quantitation between strains. Quantitation is shown to the right directly above the corresponding regions of the $\mathrm{M}$ element. Each bar represents the average of at least four independent reactions after correction for background (as measured in the -RT lane) and template amount differences between strains as determined by quantitation of $\alpha$-tubulin RNA (TubA). The open bar, wild type (wt); hatched bar, $M+$ lines $(M+)$; solid bar, Nulli 4 strains (n4). The scale is in arbitrary units. 
identical RNA samples used for the Northern blot analysis in Figure 1 with riboprobes specific for each strand of the $\mathrm{R}$ element, we detected weak, but reproducible hybridization (data not shown). To more extensively analyze this transcription, we used a similar semiquantitative RT-PCR strategy as we had used to analyze M element transcription (Fig. 5). As a template for RT-PCR, we used pooled RNA isolated from $3.5,5$, and $7 \mathrm{~h}$ conjugating cells. We detected transcription of the germlinelimited sequence and the immediate flanking regions. Thus, the pattern and timing of transcription of the $\mathrm{R}$ element is similar to that of the $M$ element.

We were interested to know whether the germlinelimited $\mathrm{R}$ element also carries the sequences in cis to induce its own expression. We generated strains that contained the $\mathrm{R}$ element in their macronuclei. We then crossed these R+ strains and again isolated RNA at 3.5, 5, and $7 \mathrm{~h}$ of conjugation for RT-PCR analysis. R-element transcripts levels were significantly increased in $\mathrm{R}+$ cells relative to wild type. This was particularly true for transcripts detected with PCR reactions $\mathrm{R} 1$ and $\mathrm{R} 4$, which span the left and right junctions, respectively, between germline-limited DNA and macronucleus-destined sequences. Transcript levels from these portions of the element were increased in abundance 10- to 20-fold over wild-type levels. Therefore, both the $M$ and $\mathrm{R}$ elements are able to induce their own transcription when present in the macronucleus. Transcription of the boundaries of the R element was more highly induced than its center. In contrast, transcription of the center region of the $M$ element was more highly induced. We suspect that this apparent contrast is more a reflection of the larger size of the R element and differences between the two RT-PCR analyses rather than a significant difference in transcription, but we have not further explored this issue. Nota- bly, transcription of the $\mathrm{R}$ element in $\mathrm{M}+$ strains was comparable to that of wild-type cells, indicating that the increase of transcription in $M+$ cells is limited to the $M$ element (Fig. 5).

The $\mathrm{M}$ and $\mathrm{R}$ elements are found adjacent to one another in the germline genome. We were curious to investigate the transcription of germline-limited sequences located in other genomic regions. To gain a more global picture of transcription of these sequences, we chose to look at the transcription of a class of moderately repetitive sequences that undergo programmed DNA deletion. The $7.2 \mathrm{kbp}$ sequence of clone pTt2512 is homologous with germline-limited sequences present in 50 to 200 copies dispersed among the different micronuclear chromosomes (Yao 1982). We hybridized a Northern blot containing RNA from conjugating cells with radiolabeled pTt2512 DNA (Fig. 6). Strikingly, we detected heterogeneous transcripts ranging from $<200 \mathrm{~b}$ to nearly $1 \mathrm{~kb}$ in size that were most abundant between 7 and $9 \mathrm{~h}$ of conjugation. The size distribution of these transcripts is very similar to the M-element transcripts that we observed during the same developmental stage. We did not detect transcription before $7 \mathrm{~h}$ of conjugation, which is in contrast to M-element transcription that was abundant by $5 \mathrm{~h}$ (Fig. 1A). The difference in timing of germline sequence transcription detected with the pTt2512 probe and the M-element probe is unclear, but this difference may indicate that these two sequences represent different classes of eliminated DNA. Nevertheless, transcription of this moderately repetitive sequence would appear to indicate that transcription of the germline-limited DNA is a global phenomenon. Two other germline-limited sequences (Heinonen and Pearlman 1994; Katoh et al. 1993) that we have analyzed also appear to be similarly transcribed (data not shown). For

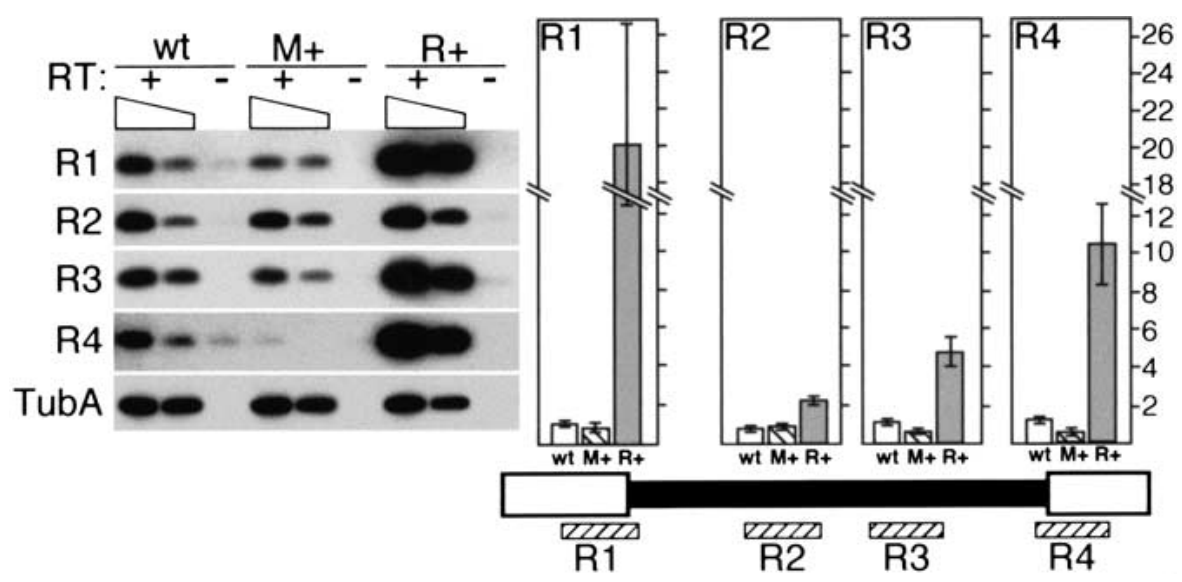

Figure 5. The R element specifically induces its own transcription. The transcription of the R element and immediate flanking DNA was compared between wild-type, $\mathrm{M}+$ (macronuclei containing copies of the $\mathrm{M}$ element), and $\mathrm{R}+$ (macronuclei containing copies of the $\mathrm{R}$ element) strains using semiquantitative RT-PCR. Transcription through four $\sim 200$ bp regions of the element designated R1 through $\mathrm{R} 4$ was assayed. For $+\mathrm{RT}$ reactions, both the equivalent of $1 \mu \mathrm{g}$ total RNA (left lane of each) and $0.3 \mu \mathrm{g}$ of RNA (right lane of each) was assayed, which is indicated by the sloping box. After amplification, PCR products were detected by Southern blot analysis using an $\mathrm{R}$ element probe. Quantitation by phosphorimager analysis is shown to the right directly above the corresponding regions of the $\mathrm{R}$ element. Each bar represents the average of at least four independent reactions after correction for background (as measured in the -RT lane) and template amount differences between strains as determined by quantitation of $\alpha$-tubulin RNA (TubA). The open bar, wild type $(\mathrm{wt})$; hatched bar, $\mathrm{M}+$ lines $(\mathrm{M}+)_{\text {; }}$ shaded bar, $\mathrm{R}+$ lines $(\mathrm{R}+)$. The scale is discontinuous and given in arbitrary units. 


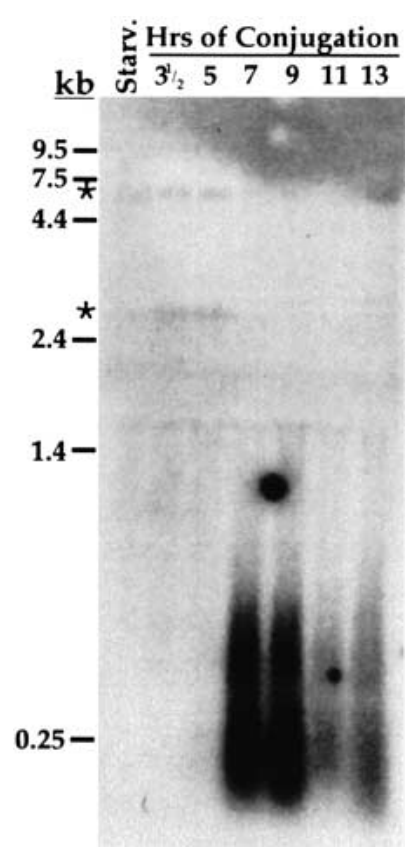

Figure 6. The repetitive germline-limited sequence of pTt 2512 is transcribed. A Northern blot containing total RNA (15 $\mu \mathrm{g} /$ lane) isolated from starved or synchronously conjugating Tetrahymena cells was hybridized with radiolabeled DNA from plasmid pTt2512. The positions of migration of RNA size standards (GIBCO-BRL) are indicated to the left. Asterisks indicate lowabundance transcripts of $\sim 3$ and $\sim 7 \mathrm{~kb}$ detected in starved and conjugating cells that have not been further studied.

all these germline-limited sequences, their transcripts are present during the stage of development when developing micronuclei and macronuclei differentiate from one another. The fact that we can detect transcription of all the germline-limited sequences that we have examined strongly implicates an important role of this nongenic transcription in the DNA deletion process.

\section{Transcription is necessary for efficient} M-element excision

As a first step toward addressing the role of transcription in DNA rearrangement, we have looked at the effect of blocking transcription during nuclear development. We treated conjugating Tetrahymena cells with the tran- scription inhibitor actinomycin $\mathrm{D}$ during the times that we detected abundant M-element transcripts and examined the effect on M-element excision. Continuous treatment with actinomycin $\mathrm{D}$ after formation of zygotic nuclei (which occurs in wild-type strains at 4.5 to $5 \mathrm{~h}$ of conjugation) does not affect the initial development of new macronuclei, but does block late developmental events such as resorption of maternal macronuclei (Ward and Herrick 1996). Therefore, we suspected that a pulse of actinomycin D during the peak of M-element transcript accumulation (5 to $7 \mathrm{~h}$ ) should not significantly impair developmental progression. We added the drug to cells at $2.5 \mathrm{~h}$ of conjugation and at half hour intervals between 4.5 and $7 \mathrm{~h}$. After a $3 \mathrm{~h}$ treatment, individual mating pairs were transferred to drug-free medium and allowed to complete development. Cytological examination of cells showed that addition of actinomycin D at $2.5 \mathrm{~h}$ caused cells to arrest in meiosis during treatment as shown previously (Kaczanowski and Kaczanowska 1996). Addition of the drug at $4.5 \mathrm{~h}$ or later did not affect developmental progression during the $3 \mathrm{~h}$ treatment (data not shown). The majority of isolated pairs treated at 4.5 to $7 \mathrm{~h}$ survived to produce progeny, although somewhat fewer survived than those of untreated cells (Table 1). Thus, blocking transcription during this time was not catastrophic to development.

We examined the efficiency of M-element rearrangement in the progeny of treated cells using a semiquantitative PCR assay (see Materials and Methods). The results are summarized in Table 1. A rather high proportion of progeny $(25.6 \%-37.5 \%)$ of pairs treated at either $4.5,5$, or $5.5 \mathrm{~h}$ showed observable failure of M-element excision. The fraction of progeny that failed to excise the $M$ element progressively decreased when actinomycin D treatment started at $6 \mathrm{~h}$ or later. Southern blot analysis of a subset of the progeny showed that a similar proportion of these cells also failed to excise copies of the $\mathrm{R}$ element (data not shown). Addition of actinomycin D at $2.5 \mathrm{~h}$ had only a modest effect on excision. Because these cells arrested in meiosis, they did not proceed through the developmental stages during which actinomycin D treatment inhibited M-element rearrangement until after removal from drug when transcription could resume. No failure of M-element excision was observed in untreated cells consistent with the previously observed high fidelity of rearrangement (Austerberry and Yao 1987). In none of the progeny lines was M-element exci-

Table 1. Frequency of M-element excision failure resulting from actinomycin $D$ treatment during conjugation

\begin{tabular}{|c|c|c|c|c|c|c|c|c|}
\hline & \multicolumn{8}{|c|}{ Time of actinomycin D addition } \\
\hline & untreated & $2.5 \mathrm{~h}^{\mathrm{a}}$ & $4.5 \mathrm{~h}^{\mathrm{a}}$ & $5 \mathrm{~h}$ & $5.5 \mathrm{~h}$ & $6 \mathrm{~h}$ & $6.5 \mathrm{~h}$ & $7 \mathrm{~h}$ \\
\hline$\%$ failed excision $(\mathrm{N})^{1}$ & $0(36)$ & $6.2(16)$ & $37.5(16)$ & $25.6(39)$ & $33.3(39)$ & $16.6(32)$ & $9.6(31)$ & $3.1(32)$ \\
\hline$\%$ progeny $^{2}$ & 93.2 & 44.3 & 69.3 & 70.4 & 81.1 & 63.6 & 77.3 & 90.9 \\
\hline
\end{tabular}


sion completely blocked. In lines showing failed excision, only one-quarter to one-half of the M-element copies typically failed to rearrange (Fig. 7). This may be because of the fact that we were unable to treat cells with actinomycin $\mathrm{D}$ during the entire period of M-element transcription without arresting development. Nevertheless, these results indicate that transcription starting between 4.5 and $5.5 \mathrm{~h}$ of conjugation is critical for efficient rearrangement of the $M$ element. The initial peak of $M$ element transcription at $5 \mathrm{~h}$ corresponds to the time window $(4.5-5.5 \mathrm{~h})$ during which inhibition of transcription had the greatest effect on excision. Therefore, we propose that inhibition of M-element transcription directly interferes with excision. We cannot rule out the possibility that actinomycin D treatment inhibited expression of genes essential for DNA deletion. However, DNA deletion occurs several hours after we removed cells from the drug, which allows time for critical gene expression before excision. Furthermore, if mating cells were unable to recover from the block of gene expression, one might expect a more severe effect on the rate of progeny production of treated cells as actinomycin D would have blocked expression of all genes essential for development. Therefore, we believe that inhibition of nongenic transcription of the $M$ element likely caused the failure of excision.

\section{Discussion}

We have investigated the transcription of germline-limited sequences that are excised from the developing somatic genome of Tetrahymena. We first detected tran-

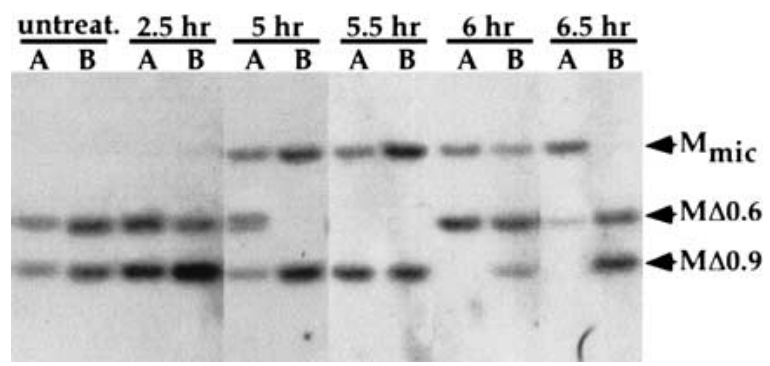

Figure 7. Actinomycin D treatment blocks efficient M-element rearrangement. The first two lanes contain DNA of progeny lines of untreated cells. Each successive pair of lanes contains the DNA isolated from two selected progeny lines, A and $\mathrm{B}$, surviving actinomycin $\mathrm{D}$ treatment during conjugation. The time of conjugation when actinomycin D was added is indicated above each lane. DNA samples were digested with HindIII, and Southern blots were hybridized with a probe specific to DNA immediately flanking the M element. The position of the DNA fragments corresponding to the unrearranged $M$ element, Mmic, and the two alternatively rearranged forms, $M \Delta 0.6$ and $\mathrm{M} \Delta 0.9$, are indicated by arrowheads. Typically, one or both rearranged forms are present in the macronucleus of each line. The presence of the unrearranged $\mathrm{M}$ element in some lines is indicative of failed rearrangement as the micronuclear DNA of these lines is not visible in this exposure. scription of the $M$ element within a few hours of the start of conjugation. This initial activation of $\mathrm{M}$-element transcription coincides with earlier reports of $3 \mathrm{H}$-uridine incorporation observed in meiotic micronuclei (Martindale et al. 1985; Sugai and Hiwatashi 1974). The relationship between the transcription of micronucleus-limited sequences and the bulk of transcription occurring in meiotic micronuclei remains to be elucidated. Transcripts were most abundant between 5 and $7 \mathrm{~h}$, the time during which zygotic nuclei form and begin their differentiation into micronuclei or macronuclei. These transcripts were quite heterogeneous in size and were produced by transcription of both DNA strands. It is unclear whether the heterogeneity of transcript size is because of multiple start and stop sites of transcription or because of rapid degradation of these transcripts. We found no evidence of polyadenylation of M-element transcripts, which is consistent with the fact that the M element is a noncoding sequence.

In addition to the $\mathrm{M}$ element, we showed that the $\mathrm{R}$ element and the moderately repetitive sequences of pTt2512 are transcribed during conjugation. In fact, all five unique or repetitive germline-limited sequences that we have examined show developmentally regulated transcription. This raises the possibility that many or most of these germline sequences are transcribed, which we find quite interesting because these elements make up as much as $15 \%$ of the germline genome (Yao and Gorovsky 1974). Transcription of germline-limited sequences is not limited to Tetrahymena. Developmentally regulated transcription of the repetitive, transposon-like Tec elements of the hypotrichous ciliate Euplotes crassus has been described (Jaraczewski et al. 1994). Although this report focused on the analysis of polyadenylated transcripts potentially involved in the expression of the elements' open reading frames, we are quite intrigued by their description of faint smears of hybridization on Northern blots of polyA+ RNA, which may represent a similar transcriptional phenomenon as we describe here. Furthermore, heterogeneous tran scripts of the micronucleus-limited telomere-bearing elements (TBE) of Oxytricha (Herrick et al. 1985) have been observed (K. Williams and G. Herrick, pers. comm.). These TBE transcripts appear, at least in many cases, to start within flanking DNA and can be of either strand polarity. We find the similarity of these transcripts with M-element transcripts quite striking. The apparent conservation of developmental transcription of germlinelimited DNA among these rather distantly related ciliates we believe underscores its importance in the regulation of DNA deletion.

Cis-acting sequences that are necessary to induce transcription appear to be contained within these germlinelimited elements. Both the $\mathrm{M}$ and $\mathrm{R}$ elements are transcribed even when they are present in the maternal macronucleus, indicating that their transcription is not restricted to one type of nucleus. The same $0.6 \mathrm{kbp}$ germline-limited region that induces transcription of the $M$ element also contains sequences essential for its excision from the developing somatic genome (M.C. Yao, 
C.H. Yao, R. Callahan, and R. Godiska, unpubl.). Whether the cis-acting sequences that are required for excision are the same as those that induce transcription is not clear, but it leads us to suggest that one way that these elements confer their own elimination is by induction of this nongenic transcription. This idea is supported by the fact that M-element elimination was blocked in conjugating cells by treatment with the transcription inhibitor, actinomycin D.

The transcription of intergenic regions and other noncoding sequences is somewhat of an enigma. This point may best be illustrated by transcription of oocyte lampbrush chromosomes (for review, see Callan 1982). Extensive RNA synthesis occurs on the lampbrush lateral loops that in some cases span $100 \mathrm{kbp}$ or more of DNA and include the coding and intergenic regions of several genes (Bromley and Gall 1987; Diaz and Gall 1985). The biological significance of this massive transcription, or even the lampbrush chromosome itself, has yet to be explained, but it is not difficult to imagine a role for transcription in creating or maintaining this unique chromosomal architecture. Similarly, transcription may have a role in establishing localized chromosomal domains. It has been shown recently that intergenic transcription of the human $\beta$-globin locus correlates with developmental chromatin remodeling that may lead to the differential expression of the genes in the cluster (Gribnau et al. 2000). Together, these observations support a view that intergenic transcription is involved in chromatin remodeling necessary for proper gene regulation. Chromatin remodeling proteins have been shown to associate with the RNA polymerase II machinery (Cho et al. 1998; Wilson et al. 1996; Wittschieben et al. 1999); thus, transcription through a locus may allow these proteins to carry out their function.

How might transcription stimulate DNA deletion? Transcription has been associated with increases in both meiotic and mitotic recombination in budding yeast (Bratty et al. 1996; Thomas and Rothstein 1989; VoelkelMeiman et al. 1987). In addition, mammalian V(D)J recombination is preceded by transcription of the unrearranged locus (Blackwell et al. 1986; Schissel and Baltimore 1989; Yancopoulos and Alt 1985; Yancopoulos et al. 1986). Recently, both Ig and TCR gene rearrangements have been shown to correlate with histone acetylation, which is indicative of an open chromatin structure that would allow the recombination machinery access to these loci (McBlane and Boyes 2000; McMurray and Krangel 2000). By analogy, transcription of the germline-limited DNA of Tetrahymena would ensure that these elements are accessible to the proteins that perform DNA deletion. Actinomycin D treatment of conjugating cells indicated that transcription between 4.5 and $5.5 \mathrm{~h}$ of conjugation is necessary for the efficient excision of the $M$ element. The transcripts are most abundant between 3.5 and $7 \mathrm{~h}$ when the condensed germline chromatin of the micronucleus must begin to make the transition to become the active chromatin of the new macronucleus. This is well before the time (12-
$14 \mathrm{~h}$ ) when these DNA elements are actually excised from the developing macronucleus (Austerberry et al. 1984). Therefore, the timing of this transcription is consistent with its involvement in an early step in their excision in which these sequences might be targeted for elimination. Considering that $\sim 6000$ germline-limited sequences are dispersed throughout the chromosomes, one could take this idea one step further and postulate that this transcription is important for the chromatin remodeling that must take place for the developing nucleus to become fully active.

Could the deletion element RNA have a role in DNA elimination? Several studies suggest that spliced switched transcripts are required for class switch recombination of Ig heavy chain genes (Hein et al. 1998; Lorenz et al. 1995). How these transcripts are involved is still unknown. The list of functional noncoding RNAs continues to grow (Erdmann et al. 1999). However, unlike these $\mathrm{M}$-element transcripts that are heterogeneous in size and nonpolyadenylated, most of these noncoding RNAs are found as defined, polyadenylated species. For example, the Xist and roX RNAs involved in dosage compensation in mammals and flies, respectively, are RNAs of discrete sizes (Amrein and Axel 1997; Brockdorff et al. 1992; Brown et al. 1992; Meller et al. 1997). We cannot rule out the possibility that a minority of M-element transcripts is of fixed size and that these are the biologically active species, but we have no data to support this idea. We are intrigued by the recent report that the conserved protein motif, the chromodomain, has been shown to interact with RNA (Akhtar et al. 2000). Expression of the chromodomain containing Pddlp during the first 7 to $8 \mathrm{~h}$ of conjugation, the same period in which we detect germline transcription, is essential for elimination of the $\mathrm{M}$ and $\mathrm{R}$ elements (Coyne et al. 1999). It is compelling to think that deletion element transcripts guide the localization of Pddlp to these sequences before excision (Madireddi et al. 1996). It will be important to determine whether the localization of Pdd1p with these sequences requires their transcription, and whether the RNA transcripts are associated with the DNA deletion machinery.

We previously showed that $\mathrm{M}$ - and R-element rearrangement during conjugation is inhibited when copies of these elements are placed into parental macronuclei before mating (Chalker and Yao 1996). The molecular basis for this epigenetic regulation of DNA deletion has yet to be determined. Our finding that the elements located in parental macronuclei are transcribed raises the possibility that the RNAs produced may participate in this inhibitory process. These RNAs could either interfere with the localization of DNA deletion proteins or alternatively, perturb appropriate chromatin structure by pairing with the unrearranged sequence in developing macronuclei before excision. Although these mechanisms are speculative, this study may provide some of the first clues toward a molecular understanding of this and similar epigenetic phenomena previously documented in Tetrahymena and other ciliates (for review, see Yao et al. 2001). 


\section{Materials and methods}

Strains and growth conditions

All growth and manipulations of Tetrahymena were performed as described previously (Asai and Forney 1999; Gorovsky et al. 1975). T. thermophila inbred B strains CU427 (Chx/Chx [V1, cy-s]) and CU428 (Mpr/Mpr [VII, mp-s]) were used as wild-type strains in all experiments. CU357 (Nulli 4 [IV]) and CU367 (Nulli 4 [VII]) were kindly provided by Peter Bruns (Cornell University). $\mathrm{M}+$ and $\mathrm{R}+$ caryonidal lines were generated by crossing transformed lines HC76-M5B, HC81-M3A, or HC81-R7A (Chalker and Yao 1996) with strain B2086 (II) obtained from Peter Bruns. The presence of the M or R element in macronuclei of progeny lines was assessed by Southern blot analysis (data not shown).

\section{RNA isolation and Northern blot analysis}

Total RNA was isolated from vegetative, starved, or mating Tetrahymena cells by RNAsol extraction (Fan et al. 1999). Northern blot analysis was performed essentially as described in Ausubel et al. (1990). After prehybridization in Church's hybridization buffer (Church and Gilbert 1984), nylon membranes were hybridized with either radiolabled riboprobes in $6 \times \mathrm{SSC} /$ $40 \%$ formamide $/ 2 \times$ Denhardt's $/ 10 \%$ dextran sulfate at $55^{\circ} \mathrm{C}$ to $60^{\circ} \mathrm{C}$ or to DNA probes in Church's hybridization buffer at $65^{\circ} \mathrm{C}$ for 16 to $36 \mathrm{~h}$. Filters were washed in $1 \times$ SSC/0.5\% SDS or $1 \times$ $\mathrm{SCP} / 1 \%$ sarcosyl, respectively, four times for 15 to $30 \mathrm{~min}$ each at $70^{\circ} \mathrm{C}$, and then allowed to expose X-ray film.

\section{Hybridization probes}

Plus- and minus-strand M-element riboprobes were synthesized from pMint7 and pMint2, respectively. These plasmids each contain a $584 \mathrm{bp}$ fragment of the $\mathrm{M}$ element corresponding to sequences between nucleotides 561 and 1145 of the published sequence (Austerberry and Yao 1988) inserted in opposite orientations into vector pCR2.1 (Invitrogen). Between 1 and $2 \mu \mathrm{g}$ of plasmid DNA, linearized with BamHI, was used for in vitro transcription reactions using T7 RNA polymerase (Ambion) in the presence of $0.0125 \mathrm{mM} \alpha 32 \mathrm{P}-\mathrm{UTP}$ ( $800 \mathrm{Ci} / \mathrm{mmole}$ ), 0.05 $\mathrm{mM}$ unlabeled UTP, and $0.5 \mathrm{mM}$ each of ATP, GTP, and CTP.

DNA fragments were radiolabeled using $\alpha^{32} \mathrm{P}$-dATP (3000 Ci/ mmole) and random hexamers as previously described (Feinberg and Vogelstein 1983). Plasmid pTt2512 (Yao 1982) was digested with $H h a \mathrm{I}$, and the three largest DNA fragments were isolated and used in labeling reactions. The Actin, Pdd1, and $\alpha$-tubulin gene probes each consisted of PCR fragments containing the entire coding sequence amplified from Tetrahymena genomic DNA. Each PCR fragment was cloned into pCRII or pCR2.1 (Invitrogen), then isolated from vector sequences before radiolabeling. The M- and R-element probes used to detect RT-PCR products contained both element and flanking DNA isolated from plasmids pDLCM1 and pDLCR4, respectively (Chalker and Yao 1996). The 17s rRNA probe was oligonucleotide 5' GGAAATACTTTTTGCGCCAG $3^{\prime}$ end-labeled with gamma $\gamma^{32} \mathrm{P}$-ATP $(3000 \mathrm{Ci} / \mathrm{mmole})$ using T4 polynucleotide kinase.

\section{$R T-P C R$}

All RT reactions, PCR, and Southern blot analyses were performed essentially as described previously (Ausubel et al. 1990). Before RT reactions, RNA was treated with DNAseI $>30$ min at $37^{\circ} \mathrm{C}$. DNAseI was inactivated at $65^{\circ} \mathrm{C}$ for $10 \mathrm{~min}$ and removed by phenol/chloroform $(1: 1)$ extraction. For each RT reaction using M-element specific primers, $5 \mu \mathrm{g}$ of total RNA was reverse transcribed using $100 \mathrm{ng}$ of each oligonucleotide. Up to one-tenth of these reactions was used as template for PCR. All $\mathrm{M}$ and R element-specific oligonucleotides used for RT and PCR are designated by their first and last positions relative to the published sequences (Austerberry and Yao 1987; Austerberry and Yao 1988). Element-specific RT primers were M110-129, M353-371, and M1125-1104. Minus-strand transcripts were amplified using first round primers M488-506 and M1201-1179 and nested primers were M578-601 and M1125-1104. Amplification of plus-strand transcripts was performed with first round primers M488-506 and M1125-1104 and second round primers M502-526 and M926-902.

The 3' termini of M-element transcripts were mapped using RNA ligation-mediated PCR. Approximately $100 \mu \mathrm{g}$ of total RNA isolated from 6 to $7 \mathrm{~h}$ mating cells and $4 \mu \mathrm{g}$ of polydC oligonucleotide primer were ligated using T4 RNA ligase (New England Biolabs). Two polydC18 oligonucleotides were used, one of which contained a BamHI recognition site at its $5^{\prime}$ end that served to confirm ligation. Both ends of these oligonucleotides were phosphorylated to ensure ligation of a single oligonucleotide to RNA. After ligation, RT was primed from the polydC tag using oligonucleotide QdG-5' CTGAGACGTATTG GTACCCGGAATTCCTCGAGCTGCAGGGGGGGGGGGG GG 3'. First- and second-round PCRs were performed with nested primers, which corresponded to the sequence at the $5^{\prime}$ end of QdG, and combinations of the following M-element primers: M488-505, M502-526, M578-601, and M1125-1104, M602-619, M1000-977, and M319-299. PCR products were visualized by Southern blot analysis using an M-element probe and cloned into TA vector pCR2.1.

For comparison of transcript levels between strains, equal amounts of RNA isolated from cells $3.5,5$, and $7 \mathrm{~h}$ into conjugation were pooled and reverse transcribed using random hexamers (Pharmacia). The equivalent of $1 \mu \mathrm{g}$ total RNA was used as template for PCR unless otherwise noted. PCR was performed for 23 to 29 cycles $\left(45 \mathrm{sec}\right.$ at $94^{\circ} \mathrm{C}, 40 \mathrm{sec}$ at $55^{\circ} \mathrm{C}, 1$ min at $72^{\circ} \mathrm{C}$ ) in a Robocycler 96 (Stratagene). One-third of each reaction was fractionated on agarose gels, transferred to nylon membranes, and detected with specific probes. To ensure the linearity of amplification, identical PCRs were performed with serial dilutions of control DNA templates (data not shown). Relative amounts of PCR products were determined using PhosphorImager (Molecular Dynamics). Primer pairs used for M-element reactions were: reaction M1, M2-25 and M250-236; reaction M2, M353-371 and M560-535; reaction M3, M808-836 and M1000-977; reaction M4, M1197-1216 and M1413-1390. Primers used for R-element RT-PCR were: reaction R1, R171190 and R350-326; reaction R2, R648-367 and R841-822; reaction R3, R992-1011 and R1183-1164; reaction R4, R1394-1416 and R1593-1574. Tubulin gene primers were $5^{\prime}$ TGCTCGATAA CGAAGCCATCT 3' and 5' GTGGCAATAGAAGCGTTGACA 3'.

\section{Actinomycin D treatment}

Actinomycin D was diluted to $250 \mu \mathrm{g} / \mathrm{mL}$ in $10 \mathrm{mM}$ Tris- $\mathrm{HCl}$ at $\mathrm{pH} 7.4$ just before use and added at various times to synchronously mating, wild-type cells $\left(\sim 1 \times 10^{5}\right.$ pairs $\left./ \mathrm{mL}\right)$ to a final concentration of $50 \mu \mathrm{g} / \mathrm{mL}$. Three hours after addition of drug, individual pairs were isolated into $\sim 30 \mu \mathrm{L}$ drops of $1 \times$ Spp medium. A separate aliquot of treated cells was removed and fixed in $70 \%$ ethanol for cytological analysis. After $3 \mathrm{~d}$ growth, cells in drops were checked for growth in medium containing cycloheximide $(25 \mu \mathrm{g} / \mathrm{mL})$ or 6-methylpurine $(15 \mu \mathrm{g} / \mathrm{mL})$. Successful mating resulted in progeny showing resistance to both drugs. To assess M-element rearrangement, 100 to 200 progeny cells de- 
rived from individual mating pairs were lysed in $30 \mu \mathrm{L}$ of $0.5 \%$ Tween 20, $0.5 \%$ Nonidet p40, $50 \mathrm{mM} \mathrm{KCl}, 10 \mathrm{mM}$ Tris- $\mathrm{HCl}$ at $\mathrm{pH} 8.3$, and $25 \mu \mathrm{g} / \mathrm{mL}$ proteinase $\mathrm{K}$ for $45 \mathrm{~min}$ at $65^{\circ} \mathrm{C}$, followed by $10 \mathrm{~min}$ at $94^{\circ} \mathrm{C}$, and semiquantitative, multiplex PCR was performed for $32 \mathrm{cycles}\left(45 \mathrm{sec}\right.$ at $94^{\circ} \mathrm{C}, 1 \mathrm{~min}$ at $55^{\circ} \mathrm{C}, 1.5 \mathrm{~min}$ at $72^{\circ} \mathrm{C}$ ) using $2 \mu \mathrm{L}$ of each lysate as template and three primers, M2-25, M808-836, and M1194-1176. Under these conditions, we obtained linear amplification of the unrearranged $M$ element as a $386 \mathrm{bp}$ fragment, and the two rearranged forms of the element as $279 \mathrm{bp}$ and $593 \mathrm{bp}$ fragments. Comparison of the relative intensity of each fragment, visualized on ethidium bromide-stained agarose gels, allowed determination of the efficiency of M-element excision. Any progeny line that had greater than $20 \%$ of its M-element DNA in the unrearranged, germline form was judged to have excision failure. Excision failure of these lines was confirmed by Southern blot analysis using an M-element probe as described previously (Chalker and Yao 1996).

\section{Acknowledgments}

We thank P. Fuller for providing valuable technical assistance, and Drs. D. Frank and S. Duharcourt for critical reading of the manuscript. We also thank Drs. K. Williams and G. Herrick for communicating results before publication. This work was supported by N.I.H. U.S. Public Health Service grant GM26210 to M.C.Y.

The publication costs of this article were defrayed in part by payment of page charges. This article must therefore be hereby marked "advertisement" in accordance with 18 USC section 1734 solely to indicate this fact.

\section{References}

Akhtar, A., Zink, D., and Becker, P.B. 2000. Chromodomains are protein-RNA interaction modules. Nature 407: 405-409.

Amrein, H. and Axel, R. 1997. Genes expressed in neurons of adult male Drosophila. Cell 88: 459-469.

Asai, D.J. and Forney, J.D. 1999. Tetrahymena thermophila. In Methods in cell biology (eds. L. Wilson and P. Matsudaira), Academic Press, San Diego, CA.

Austerberry, C.F. and Yao, M.C. 1987. Nucleotide sequence structure and consistency of a developmentally regulated DNA deletion in Tetrahymena thermophila. Mol. Cell. Biol. 7: 435-443.

-1988. Sequence structures of two developmentally regulated, alternative DNA deletion junctions in Tetrahymena thermophila. Mol. Cell. Biol. 8: 3947-3950.

Austerberry, C.F., Allis, C.D., and Yao, M.C. 1984. Specific DNA rearrangements in synchronously developing nuclei of Tetrahymena. Proc. Natl. Acad. Sci. 81: 7383-7387.

Ausubel, F.M., Brent, R., Kingston, R.E., Moore, D.D., Seidman, J.G., Smith, J.A., and Struhl, K. 1990. Current protocols in molecular biology. Wiley, New York.

Blackwell, T., Moore, M., Yancopoulos, G., Suh, H., Lutzker, S., Selsing, E., and Alt, F. 1986. Recombination between immunoglobulin variable region gene segments is enhanced by transcription. Nature 324: 585-589.

Bratty, J., Ferbeyre, G., Molinaro, C., and Cedergren, R. 1996. Stimulation of mitotic recombination upon transcription from the yeast gall promoter but not from other RNA polymerase I, II, III promoters. Curr. Genet. 30: 381-388.

Brockdorff, N., Ashworth, A., Kay, G.F., McCabe, V.M., Norris, D.P., Cooper, P.J., Swift, S., and Rastan, S. 1992. The product of the mouse Xist gene is a $15 \mathrm{~kb}$ inactive X-specific transcript containing no conserved ORF and located in the nucleus. Cell 71: 515-526.

Bromley, S.E. and Gall, J.G. 1987. Transcription of the histone loci on lampbrush chromosomes of the newt Notophthalmus viridescens. Chromosoma 95: 396-402.

Brown, C.J., Hendrich, B.D., Rupert, J.L., Lafreniere, R.G., Xing, Y., Lawrence, J., and Willard, H.F. 1992. The human XIST gene: Analysis of a $17 \mathrm{~kb}$ inactive X-specific RNA that contains conserved repeats and is highly localized within the nucleus. Cell 71: 527-542.

Bruns, P.J. and Brussard, T.B. 1974. Pair formation in Tetrahymena pyriformis, an inducible developmental system. J. Exp. Zool. 188: 337-344.

Callan, H.G. 1982. Lampbrush chromosomes. Proc. R. Soc. Lond. B. Biol. Sci. 214: 417-448.

Cassidy-Hanley, D., Yao, M.C., and Bruns, P.J. 1994. A method for mapping germ line sequences in Tetrahymena thermophila using the polymerase chain reaction. Genetics 137: 95-106.

Chalker, D.L. and Yao, M.C. 1996. Non-Mendelian, heritable blocks to DNA rearrangement are induced by loading the somatic nucleus of Tetrahymena thermophila with germ line limited DNA. Mol. Cell. Biol. 16: 3658-3667.

Chalker, D., La Terza, A., Wilson, A., Kroenke, C., and Yao, M. 1999. Flanking regulatory sequences of the Tetrahymena $\mathrm{R}$ deletion element determine the boundaries of DNA rearrangement. Mol. Cell. Biol. 19: 5631-5641.

Cho, H., Orphanides, G., Sun, X., Yang, X.J., Ogryzko, V., Lees, E., Nakatani, Y., and Reinberg, D. 1998. A human RNA polymerase II complex containing factors that modify chromatin structure. Mol. Cell. Biol. 18: 5355-5363.

Church, G. M. and Gilbert, W. 1984. Genomic sequencing. Proc. Nat1. Acad. Sci. 81: 1991-1995.

Coyne, R.S., Chalker, D.L., and Yao, M.-C. 1996. Genome downsizing during ciliate development: Nuclear division of labor through chromosome restructuring. Annu. Rev. Genet. 30: $557-578$.

Coyne, R., Nikiforov, M., Smothers, J., Allis, C., and Yao, M. 1999. Parental expression of the chromodomain protein $\mathrm{Pdd} 1 \mathrm{p}$ is required for completion of programmed DNA elimination and nuclear differentiation. Mol. Cell 4: 865-872.

Diaz, M.O. and Gall, J.G. 1985. Giant readthrough transcription units at the histone loci on lampbrush chromosomes of the newt Notophthalmus. Chromosoma 92: 243-253.

Erdmann, V.A., Szymanksi, M., Hochberg, A., de Groot, N., and Barciszewski, J. 1999. Collection of mRNA-like non-coding RNAs. Nucleic Acids Res. 27: 192-195.

Fan, Q., Sweeney, R., and Yao, M.C. 1999. Creation and use of antisense ribosomes in Tetrahymena thermophila. In Tetrahymena thermophila (eds. D.J. Asai and J.D. Forney), Vol. 62, pp. 533-547. Academic Press, New York.

Feinberg, A.P. and Vogelstein, B. 1983. A technique for radiolabeling DNA restriction endonuclease fragments to high specific activity. Anal. Biochem. 132: 6-13.

Godiska, R. and Yao, M.C. 1990. A programmed site-specific DNA rearrangement in Tetrahymena thermophila requires flanking polypurine tracts. Cell 61: 1237-1246.

Godiska, R., James, C., and Yao, M.C. 1993. A distant 10-bp sequence specifies the boundaries of a programmed DNA deletion in Tetrahymena. Genes \& Dev. 7: 2357-2365.

Gorovsky, M.A. and Woodard, J. 1969. Studies on the nuclear structure and function in Tetrahymena pyriformis. J. Cell Biol. 42: 673-682.

Gorovsky, M.A., Yao, M.C., Keevert, J.B., and Pleger, G.L. 1975. Isolation of micro- and macronuclei of Tetrahymena pyrifor- 
mis. Methods Cell Biol. 9: 311-327.

Gribnau, J., Diderich, K., Pruzina, S., Calzolari, R., and Fraser, P. 2000. Intergenic transcription and developmental remodeling of chromatin subdomains in the human beta-globin locus. Mol. Cell 5: 377-386.

Hein, K., Lorenz, M.G.O., Siebenkotten, G., Petry, K., Christine, R., and Radbruch, A. 1998. Processing of switch transcripts is required for targeting antibody class switch recombination. J. Exp. Med. 188: 2369-2374.

Heinonen, T.Y. and Pearlman, R.E. 1994. A germ line-specific sequence element in an intron in Tetrahymena thermophila. J. Biol. Chem. 269: 17428-17433.

Herrick, G., Cartinhour, S., Dawson, D., Ang, D., Sheets, R., Lee, A., and Williams, K. 1985. Mobile elements bounded by C4A4 telomeric repeats in Oxytricha fallax. Cell 43: 759768.

Jaraczewski, J.W., Frels, J.S., and Jahn, C.L. 1994. Developmentally regulated, low abundance Tec element transcripts in Euplotes crassus-implications for DNA elimination and transposition. Nucleic Acids Res. 22: 4535-4542.

Kaczanowski, A. and Kaczanowska, J. 1996. Induction of blocks in nuclear division and overcondensation of meiotic chromosomes with cycloheximide during conjugation of Tetrahymena thermophila. J. Eukaryot. Microbiol. 43: 380-388.

Katoh, M., Hirono, M., Takemasa, T., Kimura, M., and Watanabe, Y. 1993. A micronucleus-specific sequence exists in the 5 '-upstream region of calmodulin gene in Tetrahymena thermophila. Nucleic Acids Res. 21: 2409-2414.

Lorenz, M., Jung, S., and Radbruch, A. 1995. Switch transcripts in immunoglobulin classswitching. Science 267: 1825-1828.

Madireddi, M.T., Davis, M., and Allis, D. 1994. Identification of a novel polypepetide involved in the formation of DNA-containing vesicles during macronuclear development in Tetrahymena. Dev. Biol. 165: 418-431.

Madireddi, M.T., Coyne, R.S., Smothers, J.F., Mickey, K.M., Yao, M.-C., and Allis, C.D. 1996. Pddlp, a novel chromodomain-containing protein, links heterochromatin assembly and DNA elimination in Tetrahymena. Cell 87: 75-84.

Martindale, D.W., Allis, C.D., and Bruns, P. 1982. Conjugation in Tetrahymena thermophila: A temporal analysis of cytological stages. Exp. Cell Res. 140: 227-236.

. 1985. RNA and protein synthesis during meiotic prophase in Tetrahymena thermophila. J. Protozool. 32: 644649.

McBlane, F. and Boyes, J. 2000. Stimulation of V(D)J recombination by histone acetylation. Curr. Biol. 10: 483-486.

McMurray, M.T. and Krangel, M.S. 2000. A role for histone acetylation in the developmental regulation of $\mathrm{V}(\mathrm{D}) \mathrm{J}$ recombination. Science 287: 495-498.

Meller, V.H., Wu, K.H., Roman, G., Kuroda, M.I., and Davis, R.L. 1997. roX1 RNA paints the X chromosome of male Drosophila and is regulated by the dosage compensation system. Cell 88: 445-457.

Nikiforov, M., Smothers, J., Gorovsky, M., and Allis, C. 1999. Excision of micronuclear-specific DNA requires parental expression of Pdd2p and occurs independently from DNA replication in Tetrahymena thermophila. Genes \& Dev. 13: $2852-2862$.

Nikiforov, M., Gorovsky, M., and Allis, C. 2000. A novel chromodomain protein, Pdd3p, associates with internal eliminated sequences during macronuclear development in Tetrahymena thermophila. Mol. Cell Biol. 20: 4128-4134.

Ray, C.J. 1956. Meiosis and nuclear behavior in Tetrahymena pyriformis. J. Protozool. 3: 88-96.

Schissel, M.S. and Baltimore, D. 1989. Activation of immunoglobulin kappa gene rearrangement correlates with induc- tion of germline kappa gene transcription. Cell 58: 10011007.

Smothers, J.F., Mizzen, C.A., Tubbert, M.M., Cook, R.G., and Allis, C.D. 1997. Pddlp associates with germline-restricted chromatin and a second novel anlagen-enriched protein in developmentally programmed DNA elimination structures. Development 124: 4537-4545.

Sugai, T. and Hiwatashi, K. 1974. Cytological and autoradiographic studies of the micronucleus at meiotic prophase in Tetrahymena pyriformis. J. Protozool. 21: 542-548.

Thomas, B.J. and Rothstein, R.J. 1989. Elevated recombination rates in transcriptionally active DNA. Cell 56: 619-630.

Voelkel-Meiman, K., Keil, R., and Roeder, G. 1987. Recombination-stimulating sequences in yeast ribosomal DNA correspond to sequences regulating transcription by RNA polymerase I. Cell 48: 1071-1079.

Ward, J.G. and Herrick, G. 1996. Effects of the transcription inhibitor actinomycin D on postzygotic development of Tetrahymena thermophila conjugants. Dev. Biol. 173: 174-184.

Ward, J.G., Davis, M.C., Allis, C.D., and Herrick, G. 1995. Effects of nullisomic chromosome deficiencies on conjugation events in Tetrahymena thermophila: Insufficiency of the parental macronucleus to direct postzygotic development. Genetics 140: 989-1005.

Wilson, C.J., Chao, D.M., Imbalzano, A.N., Schnitzler, G.R., Kingston, R.E., and Young, R.A. 1996. RNA polymerase II holoenzyme contains SWI/SNF regulators involved in chromatin remodeling. Cell 84: 235-244.

Wittschieben, B.O., Otero, G., de Bizemont, T., Fellows, J., Erdjument-Bromage, H., Ohba, R., Li, Y., Allis, C.D., Tempst, P., and Svejstrup, J.Q. 1999. A novel histone acetyltransferase is an integral subunit of elongating RNA polymerase II holoenzyme. Mol. Cell 4: 123-128.

Yancopoulos, G. and Alt, F. 1985. Developmentally controlled and tissue-specific expression of unrearranged $\mathrm{V}_{\mathrm{H}}$ gene segments. Cell 40: 271-281.

Yancopoulos, G., DePinho, R., Zimmerman, K., Lutzker, S., Rosenberg, N., and Alt, F. 1986. Secondary genomic rearrangement events in pre- $\mathrm{B}$ cells: $\mathrm{V}_{\mathrm{H}} \mathrm{DJ} \mathrm{H}_{\mathrm{H}}$ replacement by a LINE-1 sequence and directed class switching. EMBO $\mathrm{J}$. 5: 3259-3266.

Yao, M.C. 1982. Elimination of specific DNA sequences from the somatic nucleus of the ciliate Tetrahymena. J. Cell Biol. 92: 783-789.

Yao, M.C. and Gorovsky, M.A. 1974. Comparison of the sequences of macro- and micronuclear DNA of Tetrahymena pyriformis. Chromosoma 48: 1-18.

Yao, M.C., Duharcourt, S., and Chalker, D.L. 2001. Genomewide rearrangements of DNA in ciliates. In Mobile DNA II (eds. N. Craig, R. Craigie, M. Gellert, and A. Lambowitz), pp. in press. Academic Press, New York. 


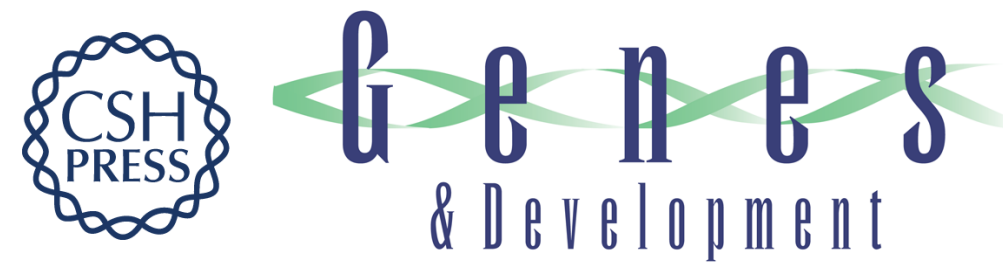

\section{Nongenic, bidirectional transcription precedes and may promote developmental DNA deletion in Tetrahymena thermophila}

Douglas L. Chalker and Meng-Chao Yao

Genes Dev. 2001, 15:

Access the most recent version at doi:10.1101/gad.884601

References This article cites 57 articles, 19 of which can be accessed free at: http://genesdev.cshlp.org/content/15/10/1287.full.html\#ref-list-1

License

Email Alerting Receive free email alerts when new articles cite this article - sign up in the box at the top Service right corner of the article or click here.

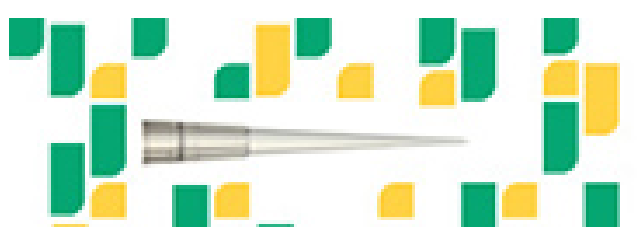

Focused on your science. 